\title{
Gallium-67 in the evaluation of sarcoidosis: correlations with serum angiotensin-converting enzyme and bronchoalveolar lavage
}

\author{
D BEAUMONT, JY HERRY, M SAPENE, P BOURGUET, JJ LARZUL, \\ B DE LABARTHE
}

\section{From the Hopital de Pontchaillou, Rennes, France}

ABSTRACT Gallium-67 $\left({ }^{67} \mathrm{Ga}\right)$ scanning was assessed for its usefulness in the evaluation and follow-up of 54 patients with sarcoidosis, both treated and untreated. Scans were repeated in 23 subjects. Serum levels of angiotensin-converting enzyme (ACE) were determined concurrently in all 54 patients and bronchoalveolar lavage was performed in 29 patients. Gallium-67 scan was effective in the detection and assessment of lesions not revealed by traditional methods of investigation, particularly those affecting the mediastinum, spleen, and salivary glands. The scan also enabled fibrotic lesions, which do not show uptake, to be distinguished from granulomatous lesions, which do-an advantage of prognostic interest particularly in patients with pulmonary lesions. Another merit of ${ }^{67} \mathrm{Ga}$ scanning was that it offered a means of following disease progression in each site. In patients showing spontaneous clearing of disease or receiving treatment the scintigraphic method was more sensitive than serum ACE determination. Scan findings showed a rough correlation with serum ACE but not with bronchoalveolar lavage findings. This suggests that the three markers probably reflect different stages of the granulomatous process. On the strength of this study the indications for gallium scanning in sarcoid patients can be defined more clearly than has previously been possible.

Sarcoidosis, a systemic granulomatous disease of unknown cause may involve such a variety of sites as to require multiple methods of investigation. The course of the disease is unpredictable. Customary investigative approaches give a relatively poor idea of the spread and activity of the granulomatous process. Recently, serum angiotensin-converting

Address for reprint requests: Dr Jean-Yves Herry, Laboratoire des Radio-Isotopes, Centre Eugéne Marquis, Centre Hospitalier de Pontchaillou, 35011 Rennes, France. enzyme $(A C E)^{1}$ and the lymphocyte count in bronchoalveolar lavage fluid ${ }^{2}$ have been proposed as markers of disease activity. The object of the present study was to assess the usefulness of ${ }^{67} \mathrm{Ga}$ uptake as another possible marker. Gallium-67 concentrates in inflammatory tissue ${ }^{3} 4$ through an imperfectly understood mechanism. It is commonly used to identify occult postoperative abscesses. Several investigators $^{5-15}$ have reported particularly intense concentration of gallium in sarcoid granulomas and, in

Table 1 Gallium-67 scanning in sarcoid patients: summarised data from the literature

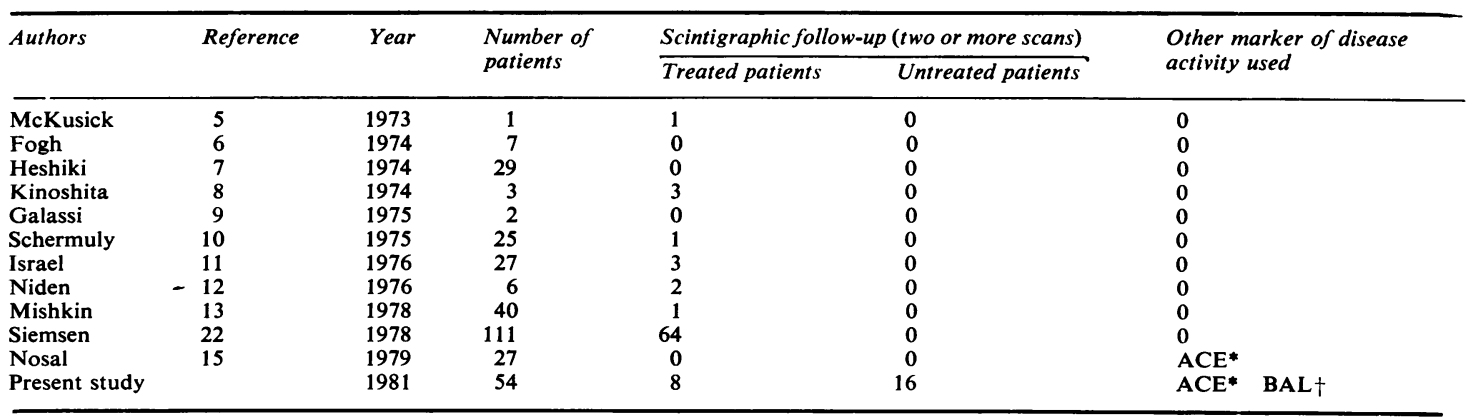


some instances, clearing of uptake in patients on corticosteroid therapy (table 1). In the present study gallium scan results were compared with those of serum ACE determination and bronchoalveolar lavage lymphocyte count and were evaluated in the follow-up of patients either treated or not.

\section{Methods}

Fifty-four patients with mediastinal and pulmonary sarcoidosis were studied. Diagnosis was based on suggestive radiographic findings supported by histological examination of one or more tissue biopsy specimens. The Kveim test was not performed. Thirty-five of the patients were males and 19 females, with ages ranging from 13 to 65 years (mean 35 years). In 24 of the patients two or three repeat scans were performed at 6-12 month intervals. Data from 70 such examinations were retained for evaluation. They formed three groups: 52 examinations performed in untreated patients with acute or chronic sarcoidosis comprised group A; eight examinations in untreated patients displaying clear signs of disease regression comprised group B; and 10 examinations in patients on corticosteroids at the time of examination comprised group $\mathrm{C}$. We did not attempt to classify the group $\mathrm{A}$ patients more precisely, since disease activity is notoriously difficult to define by classical methods. The group A patients formed three subgroups: nine patients with radiographic evidence of mediastinal adenopathy alone (group A1); 31 with pulmonary involvement (group A2); 12 with radiographic evidence of pulmonary fibrosis (group A3). Data from more than one examination in the same patient were retained only if the patient showed a change of disease status as defined by the above grouping. Thirty patients with suspected abdominal abscesses and submitted to the same investigative protocol served as controls.

Anterior and posterior total views were obtained with a whole body imager 72 hours after the intravenous injection of $60 \mu \mathrm{Ci} / \mathrm{kg}$ of ${ }^{67} \mathrm{Ga}$ citrate. Additional local camera views were obtained of the face and chest regions. ${ }^{16}$

Uptake in mediastinum, lungs, parotid glands, eyes, nose, and spleen was graded "blind" by two observers according to the classification proposed by several investigators. ${ }^{712141517}$ Grading was relative to liver activity, grade 0 signifying uptake comparable to background; grade 1 uptake less than, grade 2 uptake equal to, and grade 3 uptake greater than normal hepatic activity.

Serum ACE was assayed in all cases concurrently with ${ }^{67} \mathrm{Ga}$ scanning by the method of Cushman and Cheung ${ }^{18}$ modified to facilitate analysis of elevated values. ${ }^{19}$ In a previous study a control population had shown the upper limit of normal to be $33 \mathrm{U} / \mathrm{mll} .^{19}$

In 29 patients bronchoalveolar lavage was performed simultaneously with the above studies. Saline was pumped into the lungs through a fibreoptic bronchoscope and gently recovered in $30 \mathrm{ml}$ pulses to a total of $300 \mathrm{ml}$. The lavage fluid was analysed by the method of Reynolds, ${ }^{20}$ the alveolar lymphocyte count being expressed as number of cells $/ 100 \mathrm{ml}$ fluid. In 18 patients the T-lymphocyte population was quantified by anti-T-cell cytotoxicity.

\section{Results}

\section{CONTROLS}

Scanning data obtained from control subjects have been detailed in a previous report. ${ }^{16}$ They were

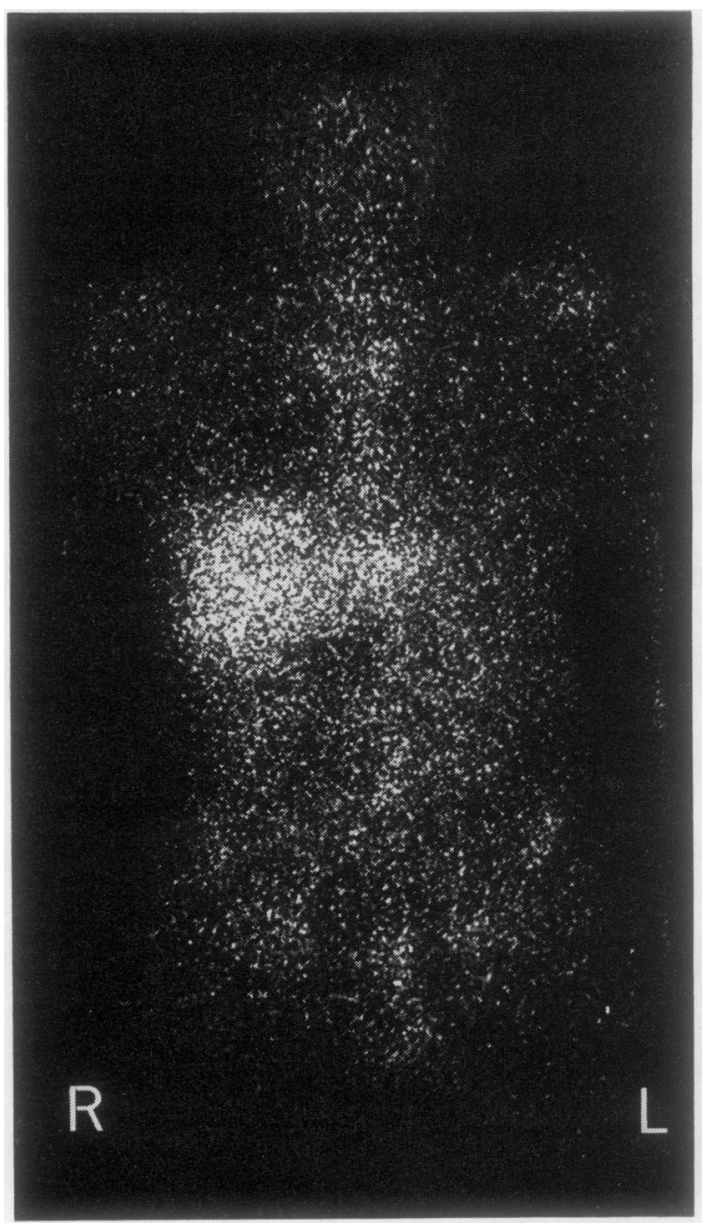

Fig 1 Normal scan (anterior view) 72 hr after iv injection of gallium- 67 . 
consistent with observations described by other investigators: $:^{21} 2272 \mathrm{hr}$ after injection, activity over the liver was pronounced in all cases, with diffuse uptake in the skeleton as a whole but no uptake in mediastinum, lungs or salivary glands (fig 1). Grade 1 uptake was noted in the eyes and nose, and breast uptake in $45 \%$ of the women examined.

PATIENTS

Of the 70 scans performed in the sarcoid patients seven were normal: of these seven, three concerned group B patients (in regression), two group C patients (receiving treatment) and two group A (chronic sarcoidosis of undetermined activity). In the remaining 63 patients sites of abnormal ${ }^{67} \mathrm{Ga}$ uptake were many and varied (figs 2,3 ) including mediastinum, lung, salivary glands, eyes, nose, spleen, and less frequently, lymph nodes, bone, and skin (table 2). Images of concurrent mediastinal and pulmonary uptake were seen in 23 cases and of

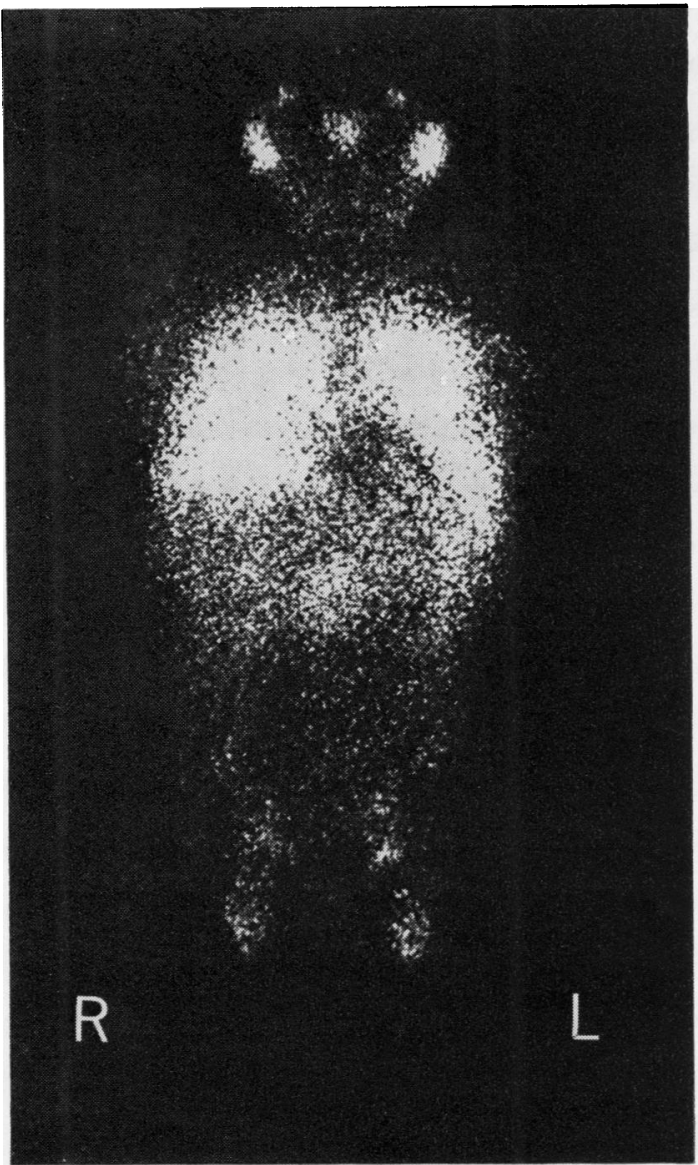

Fig 2 Scan of a patient with sarcoidosis showing diffuse uptake in both lungs and uptake in eyes, parotid glands, nose, spleen, and lymph nodes.

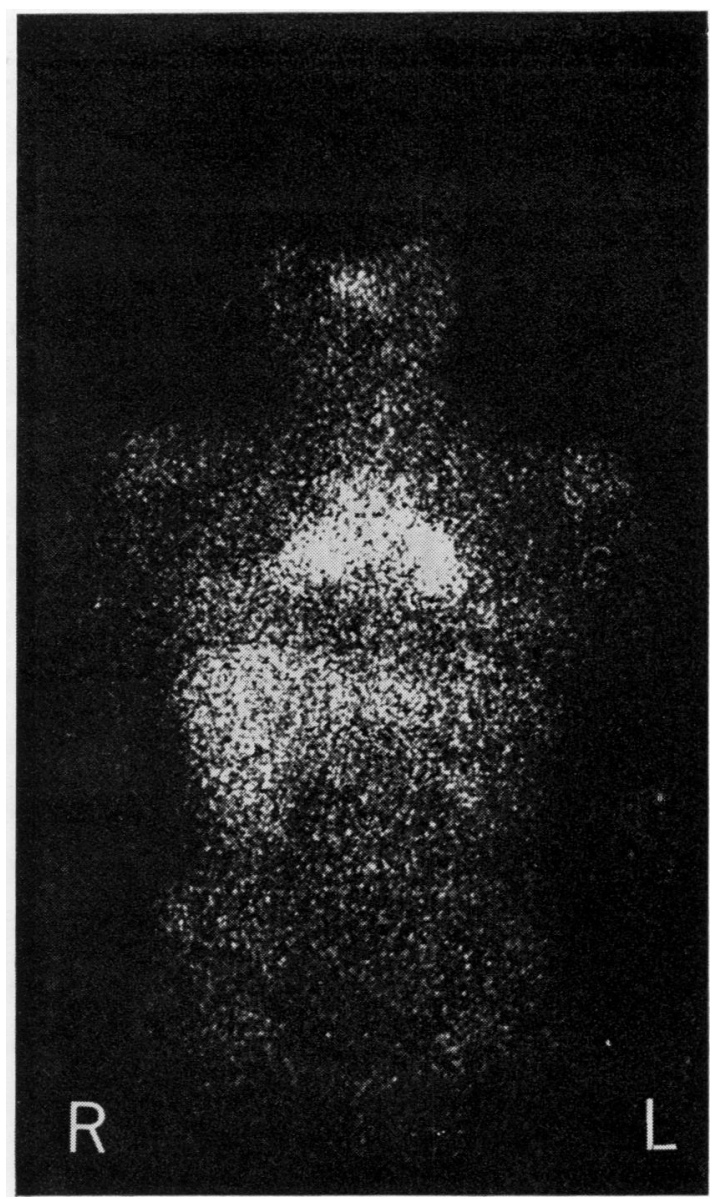

Fig 3 Scan of a sarcoid patient showing mediastinal uptake and bilateral hilar adenopathy. Slight breast uptake is noted.

Table 2 Sites of gallium- 67 uptake in sarcoid patients: data from 63 abnormal scans

\begin{tabular}{llc}
\hline Site of uptake & Number of sites & $\begin{array}{l}\text { Number of sites detected only } \\
\text { by gallium-67 }\end{array}$ \\
\hline Mediastinum & 35 & 17 \\
Lungs & 36 & 4 \\
Parotid gland & 17 & 12 \\
Eyes & 19 & 4 \\
Nose & 32 & 7 \\
Spleen & 22 & 18 \\
Lymph nodes & 5 & 0 \\
Bone & 2 & 0 \\
Skin & 1 & 0
\end{tabular}

concurrent salivary gland, mediastinal, and pulmonary uptake-particularly suggestive of sarcoidosis-in 16 cases.

Gallium-67 images of thoracic uptake were not in keeping with radiographic appearances in a number 
of cases ${ }^{23}$ (table 2). In 17 of these cases gallium scans localised mediastinal lesions undetectable on plain chest films and four patients displayed pulmonary parenchymal uptake but had normal chest films; in three of these four patients pulmonary involvement was confirmed by open lung biopsy. Abnormal radiographic appearance in the absence of ${ }^{67} \mathrm{Ga}$ uptake suggest fibrotic sequelae of sarcoidosis: this was the case in seven group A2 patients (without specific evidence of fibrosis on chest films) and four group A3 patients (with evidence of fibrosis). In the eight other group A3 patients persistence of ${ }^{67} \mathrm{Ga}$ uptake pointed to the presence of a still active granulomatous process.

Extrathoracic ${ }^{67} \mathrm{Ga}$ images pointed to sites of involvement undetected clinically or radiographically (table 2). Salivary gland ${ }^{67} \mathrm{Ga}$ uptake was seen in 12 patients with no corresponding clinical signs; in three of these patients, uptake was intense (grades 2 and 3) but gland size was normal; in nine of the 12 patients, poor lacrimal secretion on the Schirmer test pointed to associated lacrimal gland involvement consistent with a diagnosis of Sjögren's syndrome. Gallium- 67 uptake by the spleen in the absence of

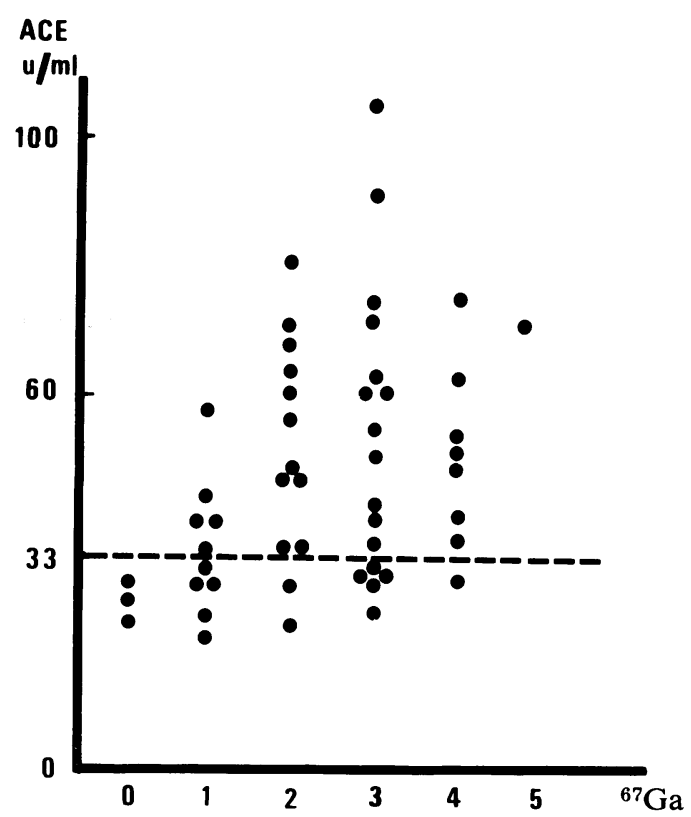

Fig 4 Relationship between number of ${ }^{67} \mathrm{Ga}$ uptake sites (mediastinum, lungs, salivary glands, spleen, and lymph nodes) and serum levels of angiotensin-converting enzyme $(A C E)$ in group $A$ untreated sarcoid patients. $A$ positive correlation is seen between the two variables $(r=0.43 ; p<0.01)$. clinical or radiographic signs of splenomegaly was observed in 18 patients, attaining grade 2 or 3 in 12 . Uptake in nose and eyes was common and, with respect to uptake patterns seen in control subjects, could be regarded as abnormal at grade 2 or 3 intensity: by this definition seven patients showed clinically asymptomatic abnormal uptake in the nose, confirmed by nasal mucosa biopsy in two patients, and four patients showed ocular involvement. In a small number of cases some uncommon sites of disease involvement were not localised by gallium scans: kidney, muscle, prostate, heart, and brain. Hepatic lesions, of course, cannot be imaged by ${ }^{67} \mathrm{Ga}$ scanning because of normally intense hepatic uptake.

The group A patients showed a correlation between serum ACE and number of sites of ${ }^{67} \mathrm{Ga}$ uptake ${ }^{24}$ (fig 4). Of the 18 patients with disease clearing either spontaneously or in response to therapy, 10 exhibited clinical signs of cure with normal ACE levels but several sites of ${ }^{67} \mathrm{Ga}$ uptake (fig 5). Alveolar lymphocyte counts in bronchoalveolar lavage fluidboth absolute and relative $\mathrm{T}$-cell counts-showed no correlation with intensity of lung radiotracer uptake (fig 6).

In 11 of the 24 patients submitted to repeat examinations, parallel patterns of development were

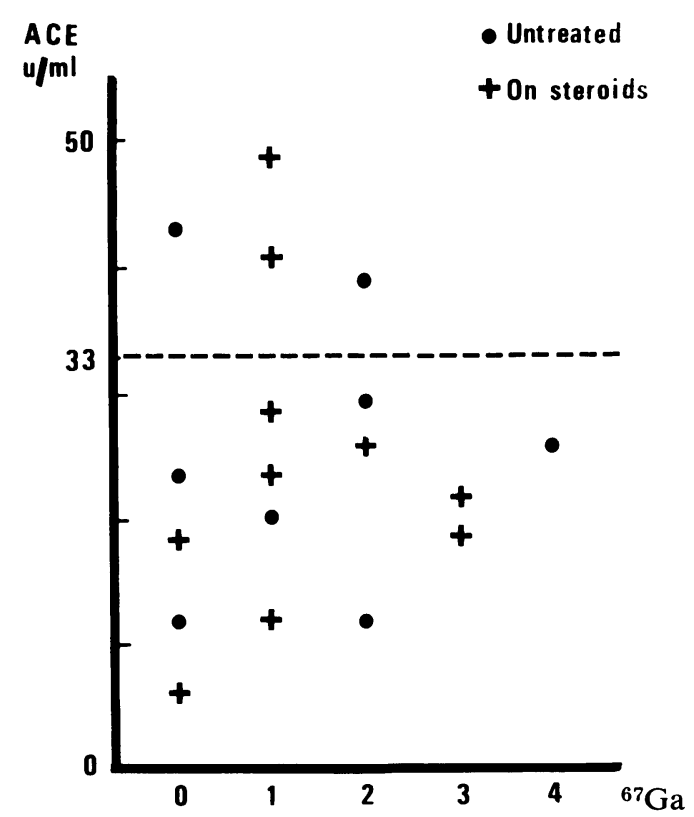

Fig 5 Relationship between number of ${ }^{67} \mathrm{Ga}$ uptake sites and serum ACE levels in sarcoid patients undergoing regression or on treatment (groups $B$ and $C$ ). Frequent persistence of ${ }^{67} \mathrm{G}$ a uptake is seen despite normal angiotensin-converting enzyme levels $(A C E)$. 
B A L

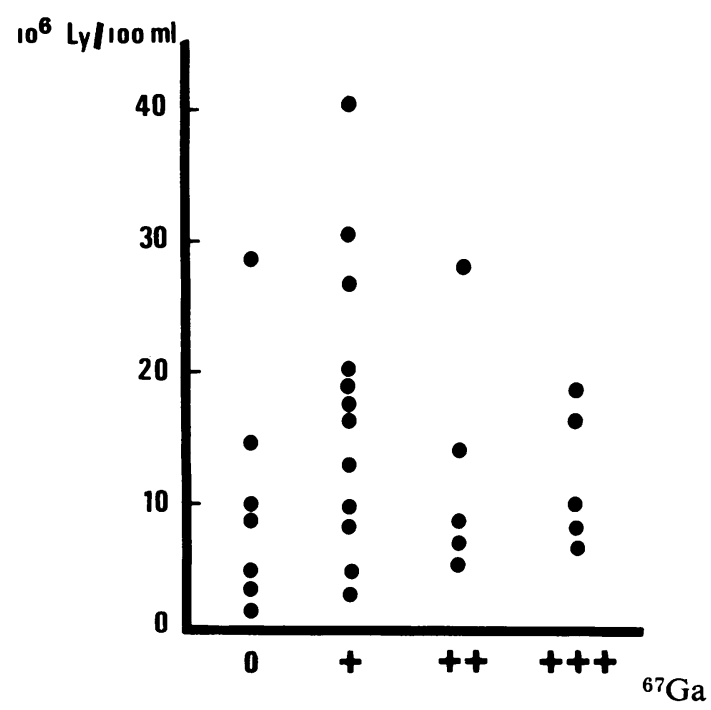

Fig 6 Relationship between bronchoalveolar lavage fluid lymphocyte count $(B A L)$ and intensity of ${ }^{67}$ Ga uptake in lungs in 29 sarcoid patients. No correlation is seen between the two variables.

seen for all aspects studied: clinical and radiographic appearances, serum ACE, and ${ }^{67} \mathrm{Ga}$ scans. In 13 cases the findings were discordant: two group B patients, for example, showed recovery of normal gallium scans before recovery of normal radiographic appearances and five group $\mathrm{C}$ patients on corticosteroids showed persistent ${ }^{67} \mathrm{Ga}$ uptake after serum ACE levels had returned to normal.

In certain cases the usefulness of ${ }^{67} \mathrm{Ga}$ scanning was particularly evident. In one patient not receiving treatment, for example, the onset of intense focal uptake of radiotracer in the spleen coincided with a sudden rise in ACE (fig 7). In another patient who had been receiving therapy for three years and had a normal serum ACE level, an optimistic prognosis was offset by images of ${ }^{67} \mathrm{Ga}$ uptake in the spleen, which, it turned out, heralded an otherwise unpredicted abrupt relapse on stopping therapy. This was followed by spontaneous regression, although uptake persisted in the spleen.

\section{Discussion}

Accurate evaluation of gallium scans in sarcoid patients can only be done if intensity of uptake for each site is compared with that in corresponding sites in control subjects. Thus, the consistent absence of pulmonary or mediastinal uptake in thoracic scans of controls lends considerable significance to the finding of such an uptake pattern in a patient with sarcoidosis-a disease almost always involving these sites. ${ }^{25}$ Uptake in the breast was seen in $45 \%$ of the female patients of the series, a rate higher than that reported by other workers. In our study, breast images were readily distinguished from patterns of pulmonary uptake, especially in posterior and lateral views. There have been a few reports of normal salivary gland uptake. 1321 In the control subjects of the present study no parotid or submaxillary uptake was noted. However, some ${ }^{67} \mathrm{Ga}$ accumulation was seen in the eyes and nose. This, according to Mishkin et $a l^{26}$ could be caused by the binding of gallium to proteins, such as transferrin and lactoferrin, in lacrimal secretions. Our experience is that only uptake of grade 2 or more should be considered abnormal. In the case of splenic uptake, which may be difficult to interpret owing to gallium accumulation in the colon, additional views are sometimes required.

Gallium scan can also localise non-sarcoid lesions and thus complicate interpretation of scan findings. Pulmonary ${ }^{67} \mathrm{Ga}$ uptake, for example, has been described in a wide variety of lung diseases, including carcinoma, infection, and the pneumoconioses. ${ }^{122} 27$ And in sarcoid patients, false-positive scans may result from bronchopulmonary superinfection, intercurrent tuberculosis or fungal infection. Further, scans should not be performed too soon after open lung biopsy or bronchoalveolar lavage since these procedures may be a source of false positive images.

Quantifying radiogallium uptake is a complex problem. The method adopted by other investigators and used in the present study is open to two major criticisms: it fails to evaluate the extent of uptake and does not clearly distinguish small focal areas of uptake from a diffuse uptake pattern of the same intensity, a shortcoming particularly pertinent to lung imaging. A pulmonary uptake index taking into account extent of uptake has been proposed ${ }^{28}$ which should make for more accurate scan assessment, although only for lung images. Another objection to the method used in most studies is that grading was based on hepatic uptake in patients with a disease frequently affecting the liver. We are currently developing a more accurate method of quantification based on the actual amount of tracer administered and the quantity accumulated in each site, whatever the intensity of hepatic uptake.

Gallium-67 scanning is not specific enough for formulation of a definite diagnosis of sarcoidosis. It can, though, offer supportive evidence for a presumptive diagnosis based on clinical and radiographic evidence especially if the radiogallium uptake pattern reflects the multisystem nature of the disease. Nosal et $a l^{15}$ consider the association of pulmonary uptake with elevated serum ACE levels to be $99 \%$ specific for 


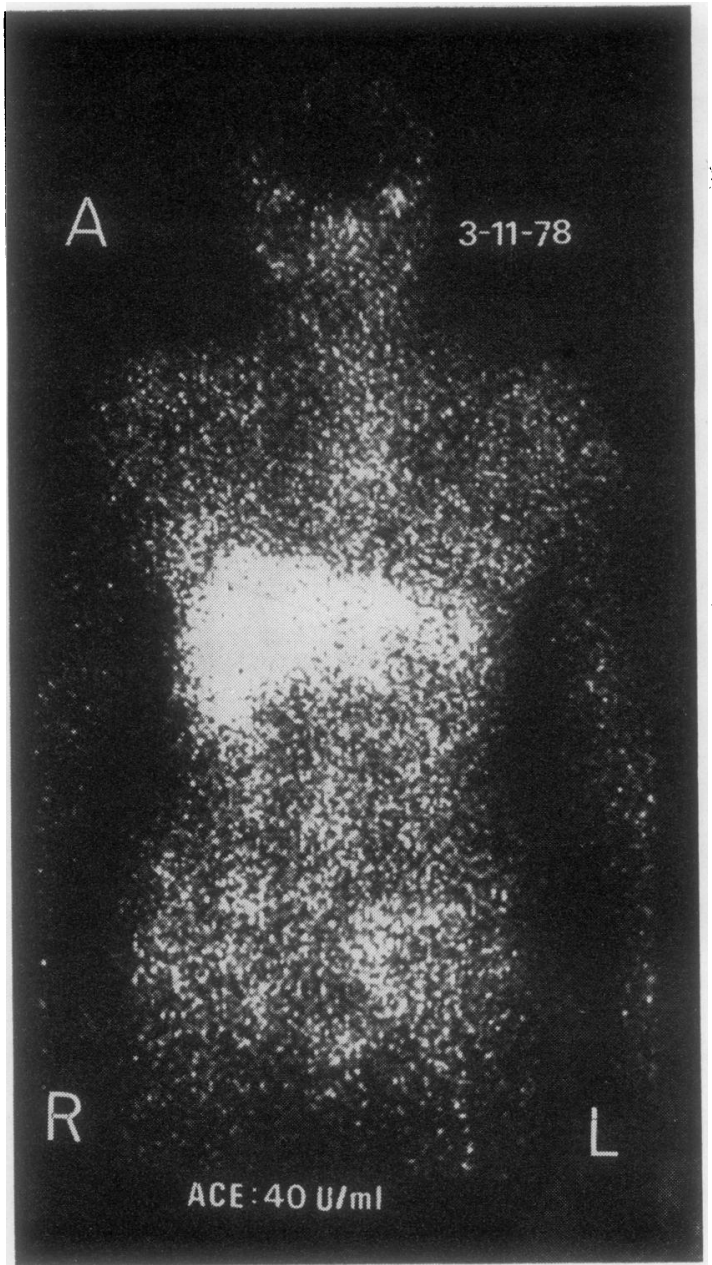

sarcoidosis. Pulmonary uptake of gallium, ${ }^{29}$ however, and sometimes elevated ACE levels ${ }^{30}$ have both been reported in silicosis patients. We share the view of De Remee $e$ al $^{31}$ that the results of these techniques must be confirmed by histopathological examination before definitive diagnosis can be established.

Gallium-67 scans sometimes merely confirm known sites of disease involvement. The advantage, though, is that with a single non-invasive investigation one has an overall view of the disease pattern, sometimes obviating the need for additional explorations, such as mediastinal tomography and scans of the salivary glands or spleen. In addition, hitherto unsuspected lesions are often detected by gallium scans. Instances of mediastinal adenopathy for example, invisible on radiographs but disclosed by gallium scintigraphy, were seen in the present study and have been described by others. ${ }^{710}$ In our experience, scanning evidence of subclinical salivary gland or splenic involvement is also common.

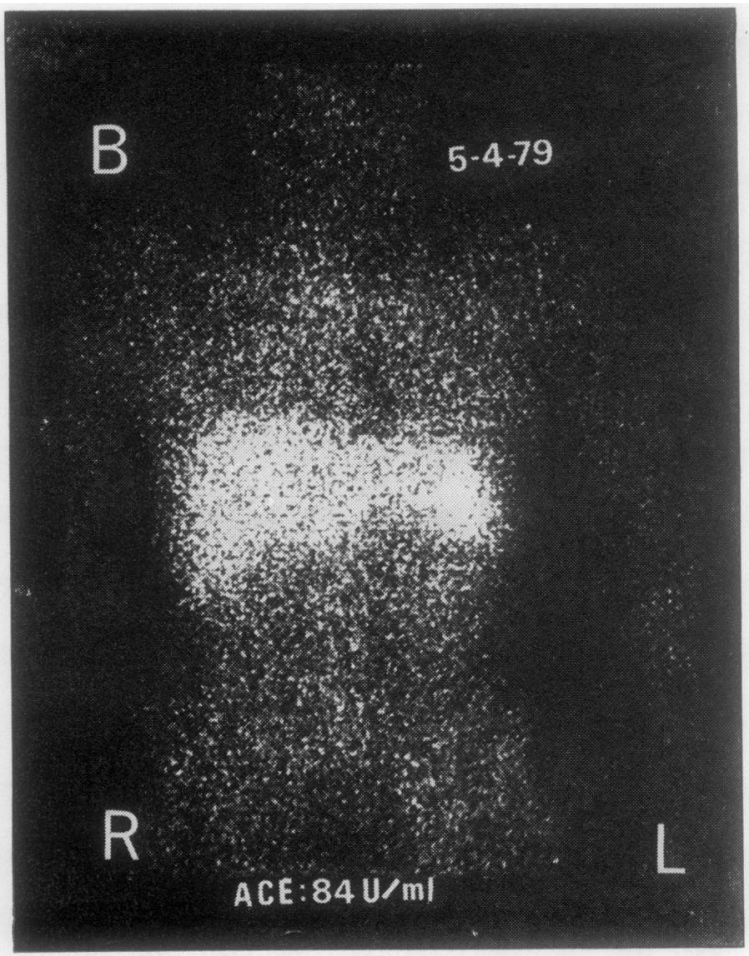

Fig 7 Gallium-67(Aand B) scans of a 25-year-old patient with untreated sarcoidosis, who showed a clear rise in serum ACE levels with no clinical or radiographic changes. ${ }^{67} \mathrm{Ga}$ scan $(B)$ showed the onset of intense focal uptake in the spleen.

Finally, in three patients in the present study ${ }^{67} \mathrm{Ga}$ scanning was more sensitive than radiography in detecting pulmonary lesions. Some lesions, however, notably of the skin or heart, were too small to show up on gallium scan. Others, as in the liver, were hidden by normal intense uptake.

With thoracic sites of involvement ${ }^{67} \mathrm{Ga}$ scans enable granulomatous lesions, which accumulate tracer, to be distinguished from fibrotic lesions, which do not. In the present series ${ }^{67} \mathrm{Ga}$ scans revealed fibrotic residua in 11 patients, including seven in whom radiography was not suggestive of fibrosis. Then again, ${ }^{67} \mathrm{Ga}$ uptake may be the only sign of granulomatous tissue within apparently purely fibrotic tissue, with clear implications for treatment planning. ${ }^{10}$

Gallium-67 scan, serum ACE level, and bronchoalveolar lavage lymphocyte count each correlates with clinical disease activity. ${ }^{31-33}$ Concordance of the results of these three investigations, however, was not as close in our study as might be expected. Our findings are in line with the observations of Gupta et $a l^{34}$ who found a significant correlation 
between ACE levels and ${ }^{67} \mathrm{Ga}$ scans but not between bronchoalveolar lymphocyte count and ${ }^{67} \mathrm{Ga}$ scans. ${ }^{35}$ They are, however, at odds with those of Crystal et al,33 who report a statistically significant correlation between the lavage fluid lymphocyte count and pulmonary ${ }^{67} \mathrm{Ga}$ uptake. Such variability reflects the difficulty of comparing data subject to widely differing modes of evaluation. Results of the three tests probably correspond to different stages of the granulomatous reaction in sarcoid patients and are thus complementary rather than concordant. ${ }^{24}$ Gallium scanning in our view, possesses two advantages: first, it provides an overall picture of the disease, whereby the progression of the granulomatous process can be followed at each site of involvement; and second, it is a more sensitive indicator of disease activity than serum ACE levels in patients in whom the disease is only mildly active or actually regressing. 1531 In our experience an additional merit of scintigraphy over ACE measurement and one that is particularly useful in the follow-up of patients receiving treatment, is that it appears less affected by corticosteroid administration.

Although ${ }^{67} \mathrm{Ga}$ scintigraphy is an innocuous, simple method of investigation and is thus suitable for outpatient use, two limiting factors must be considered: cost and radiation dose delivered to the patient. Estimated whole-body dose is $260 \mathrm{mrad} / \mathrm{mCi}$, equivalent to an average of $600 \mathrm{mrad}$ per examination; the dose to the gonads is of the same order. Although low, 3637 this dose is not a negligible consideration in young patients.

In conclusion, the findings of the present study highlight certain problem areas where ${ }^{67} \mathrm{Ga}$ scanning is useful in the investigation of sarcoidosis. These are, firstly, diffuse chronic pulmonary involvement, where granulomatous lesions can be distinguished from fibrosis; secondly, cases where several organsystems are involved and where certain sites may be missed; and thirdly, sarcoid patients on treatment, in whom ${ }^{67} \mathrm{Ga}$ scans may offer evidence of persistent disease activity and thus a solid basis for planning the dosage and duration of continued treatment. Whether or not routine use of ${ }^{67} \mathrm{Ga}$ scintigraphy should be envisaged for the diagnosis, staging and follow-up of all sarcoid patients is a question that requires further study. One factor to be considered is the abandonment of classical investigative methods, notably repeat tomography, that would result from such a decision.

\section{References}

${ }^{1}$ Lieberman J. Elevation of serum angiotensin converting enzyme (ACE) level in sarcoidosis. Am J Med 1975; 59:365-72.
${ }^{2}$ Dauber JH, Rossman MD, Daniele RP. Broncho-alveolar cell populations in acute sarcoidosis. Observations in smoking and nonsmoking patients. J Lab Clin Med $1979 ; 94: 862$.

${ }^{3}$ Tsan MF, Chen WY, Scheffel V, Wagner HN. Studies on $\mathrm{Ga}$ accumulation in inflammatory lesions. 1) $\mathrm{Ga}$ uptake by PMN leucocytes. $J$ Nucl Med 1978;19:36-44.

${ }^{4}$ Weiner R, Hoffer PB, Thakur ML. Lactoferrin: its role as a Ga-67 binding protein in polymorphonuclear leucocytes. J Nucl Med $1981 ; 22: 32-7$.

${ }^{5}$ McKusick KA, Singh Soin J, Ghiladi A, Wagner HN. 67 Gallium accumulation in pulmonary sarcoidosis. JAMA 1973;223:688.

${ }^{6}$ Fogh J, Bertelsen SV, Schmidt A. Diagnostic value of ${ }^{67} \mathrm{Ga}$ scintigraphy in chest surgery. Thorax 1974;29:26-31.

${ }^{7}$ Heshiki A, Schatz SL, McKusick KA, Bowersox DW, Singh Soin J, Wagner HN. Gallium-67 citrate scanning in patients with pulmonary sarcoidosis. Am J Roentgenol 1974;122:744-9.

${ }^{8}$ Kinoshita F, Ushio T, Maekawa A, Ariwa R, Kubo A. Scintiscanning of pulmonary diseases with ${ }^{67} \mathrm{Ga}$-citrate. $J$ Nucl Med 1974;15:227-33.

${ }^{9}$ Galassi A. Expériences de scintigraphies pulmonaires avec le gallium 67. Bronches 1975;25:240-55.

${ }^{10}$ Schermuly VW, Behrend J, Pöhls PH. Die ${ }^{67} \mathrm{Ga}$ Szintigraphie bei der Sarkoidose. Fortschr Röentgenstr 1975; 122:54-62.

${ }^{11}$ Israel HL, Park CH, Mansfield CM. Gallium scanning in sarcoidosis. Ann N Y Acad Sci 1976;278:514-6.

${ }^{12}$ Niden AH, Mishkin FS. ${ }^{67}$ Gallium citrate lung scans in interstitial lung disease. Chest 1976;69:266-8.

${ }^{13}$ Mishkin FS, Tanaka TT, Niden AH. Abnormal gallium scan patterns of the salivary gland in pulmonary sarcoidosis. Ann Intern Med 1978;89:933-5.

${ }^{14}$ Siemsen JK, Grebe SF, Sargent EN, Wentz D. Gallium-67 scintigraphy of pulmonary diseases as a complement to radiography. Radiology 1976;118:371-5.

${ }^{15}$ Nosal, A. Schleissner LA, Mishkin FS, Lieberman J. Angiotensin-I-converting enzyme and gallium scan in noninvasive evaluation of sarcoidosis. Ann Intern Med 1979;90:328-31.

${ }^{16}$ Herry JY, Beaumont D, Moisan A, Larzul JJ, Le Jeune JJ, de Labarthe B. Interprétation de la scintigraphie au Gallium 67 dans la sarcoïdose. J Biophys Med Nucl $1980 ; 4: 293-7$.

17 Gupta SM, Sziklas JJ, Spencer RP, Rosenberg R. Significance of diffuse pulmonary uptake in radiogallium scans. J Nucl Med 1980;21:328-32.

${ }^{18}$ Cushman DW, Cheung HS. Spectrophotometric assay and properties of the angiotensin-converting enzyme of rabbit lung. Biochem Pharmacol 1971;20:1637-48.

${ }^{19}$ Le Treut A, Couliou H, Delbary M, Larzul JJ, de Labarthe B, Le Gall JY. Le dosage de l'enzyme de conversion de l'angiotensine I par méthode spectrophotométrique. Clin Chim Acta 1979;98:1-4.

${ }^{20}$ Reynolds HY, Fulmer JD, Kazmierowski JA, Roberts WC, Frank MM, Crystal RG. Analysis of cellular and protein content of BAL from patients with idiopathic pulmonary fibrosis and chronic hypersensitivity pneumonitis. J Clin Invest 1977;59:165-75.

${ }^{21}$ Larson SM, Hoffer PB. Normal patterns of localization. In: Hoffer PB, Bekerman C, Henkin RE, eds. Gallium-67 Imaging. New York: John Wiley and Sons, 1978.

${ }^{22}$ Siemsen JK, Grebe SF, Waxman AD. The use of Gallium67 in pulmonary disorders. Semin Nucl Med 1978;8: 235-49.

${ }^{23}$ Herry JY, Beaumont D, Bourguet $P$ et al. Comparison of data from gallium-67 scintigraphy and thoracic radiography in the assessment of mediastinal and pulmonary 
sarcoidosis. In: Medical Radionuclide Imaging (Proc Int Symposium Heidelberg 1980) IAEA-SM-247/145:507 $-13$.

${ }^{24}$ de Labarthe B, Beaumont D, Larzul JJ et al. Angiotensinconverting enzyme, gallium-67 scintigraphy and broncho-alveolar lavage in the evaluation of mediastinal and pulmonary sarcoidosis. Proc 3rd European Conference on Sarcoidosis and Other Granulomatous Disorders, Novi Sad, 22-24 May 1980.

${ }^{25}$ Mitchell DN, Scadding JG. Sarcoidosis. Am Rev Respir Dis 1974;110:774-802.

${ }^{26}$ Mishkin FS, Maynard WP. Lacrimal gland accumulation of ${ }^{67} \mathrm{Ga} . J \mathrm{Nucl}$ Med 1974;15:630-1.

${ }^{27}$ Bekerman C, Hoffer PB, Bitran JD, Gupta RG. Gallium-67 citrate imaging studies of the lung. Semin Nucl Med 1980; 10:286-301.

${ }^{28}$ Line BR, Fulmer JD, Reynolds HY et al. Gallium-67 citrate scanning in the staging of idiopathic pulmonary fibrosis: correlation with physiologic and morphologic features and bronchoalveolar lavage. Am Rev Respir Dis 1978;118-2:355-65.

${ }^{29}$ Siemsen JK, Sargent EN, Grebe SF, Winsor DW, Wentz D, Jacobson G. Pulmonary concentration of Ga-67 in pneumoconiosis. Am J Roentgenol 1974;120:815-20.

${ }^{30}$ Groonhagen-Riska C, Kurppa K, Fyhrquist F, Selroos O. Angiotensin converting enzyme and lysozyme in silicosis and asbestosis. Scand J Respir Dis 1978;59:228-31.
${ }^{31}$ De Remee RA, Rohrbach MS. Serum angiotensin converting-enzyme in evaluating the clinical course of sarcoidosis. Ann Intern Med 1980;92:361-5.

${ }^{32}$ Larzul JJ, Letreut A, Couliou H, Beaumont D, Delava PH, Sapene M, de Labarthe B. Taux sérique de l'enzyme de conversion de l'angiotensine dans la sarcoïdose. Nouv Presse Med 1981;9:675-8.

${ }^{33}$ Crystal RG, Roberts WC, Hunnınghake GW, Gadek JE, Fulmer JD, Line BR. Pulmonary sarcoidosis: a disease characterized and perpetuated by activated lung T-lymphocytes. Ann Intern Med 1981;94:73-94.

${ }^{34}$ Gupta RG, Bekerman C, Sicilian L, Oparil S, Szidon JP. Gallium-67 citrate scanning and serum angiotensin converting-enzyme levels as indicators of disease activity in sarcoidosis. Clin Res 1979;27:705A (abstr).

${ }^{35}$ Gupta RG, Bekerman C, Catchatourian R, Sicilian L, Szidon JP. Relationship between broncho-alveolar cellular analysis and ${ }^{67}$ Gallium citrate uptake in sarcoidosis. Clin Res 1979;27:662A (abstr).

${ }^{36}$ MIRD-Dose estimate report 2, summary of current radiation dose estimates to humans from ${ }^{66} \mathrm{Ga},{ }^{67} \mathrm{Ga}$ and ${ }^{72}$ Ga-citrate. J Nucl Med 1973;14:755.

${ }^{37}$ Nelson B, Hayes RL, Edwards CL, Kniseley RM, Andrews GA. Distribution of gallium in human tissues after intravenous administration. $J$ Nucl Med 1972;13 92-100. 